\title{
Numerical Study of the High-Speed Leg of a Wind Tunnel
}

\author{
Sudheer N. Nayani ${ }^{1}$ and William L. Sellers, III ${ }^{2}$ \\ Analytical Services \& Materials, Inc., Hampton, VA 23666-1340 \\ Scott E. Brynildsen ${ }^{3}$ \\ Vigyan, Inc., Hampton, VA, 23666-1325 \\ Joel L. Everhart ${ }^{4}$ \\ NASA Langley Research Center, Hampton, VA 23681-0001
}

\begin{abstract}
The paper describes a numerical study of the high-speed leg of the NASA Langley $14 \mathrm{x}$ 22-ft Low-Speed Wind Tunnel. The high-speed leg consists of the settling chamber, contraction, test section, and first diffuser. Results are shown comparing two different sources of surface geometry, and two different unstructured grid solvers for the flow characteristics. Numerical simulations of the flow on the tunnel centerline, boundary layer profiles on the floor, and wall static pressures have been compared with experiment. Flow angularities along the test section length have also been determined.
\end{abstract}

\section{Nomenclature}

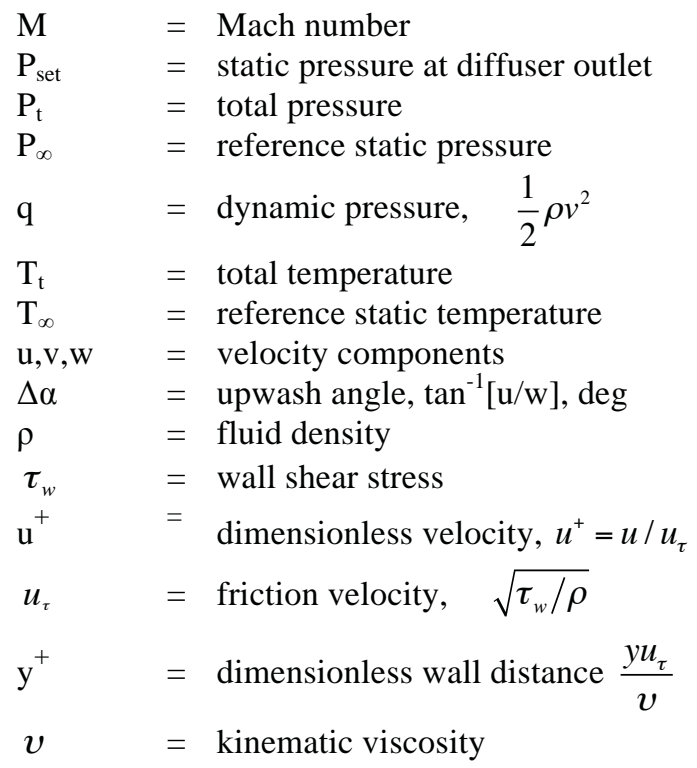

Abbreviations

$\mathrm{BC}=$ Boundary condition

CAD $=$ Computer-aided design

CFD $=$ Computational fluid dynamics

GIS = Geographic Information Systems

Sta. $\quad=$ Tunnel station, $\mathrm{ft}$.

\footnotetext{
${ }^{1}$ Senior Scientist, CFD Group, 107 Research Drive, Hampton, VA 23666-1340, AIAA Senior Member

${ }^{2}$ Senior Scientist, CFD Group, 107 Research Drive, Hampton, VA 23666-1340, AIAA Associate Fellow

${ }^{3}$ Research Engineer, GeoLab, 30 Research Drive, Hampton, VA 23666-1325

${ }^{4}$ Chief Engineer, MS 225, Hampton, VA 23681-0001, AIAA Associate Fellow
} 


\section{Introduction}

T $\mathrm{N}$ the future, aircraft will be much more integrated to enable reduced fuel burn, noise, and emissions. 1 Computational fluid dynamics (CFD) is already making significant inroads in the design process for these advanced vehicle configurations. Experimental data from wind tunnel facilities are still needed to validate the CFD methods, but also to examine off-cruise conditions, and help project the data to flight Reynolds number conditions. Successful design of these new aircraft will require the use of CFD and experiment, using the best attributes of both techniques.

To validate CFD methods, experiments must be completely simulated and that may include modeling tunnel walls, model support systems, or any other features that may affect the wind tunnel data itself. From the experimental side it means one must truly understand the operations of the wind tunnel, the flow characteristics, and wall corrections. The experimentalist must understand what is needed to provide the proper boundary conditions for CFD simulations and provide that data in the most accurate way possible.

Wind tunnel wall corrections ${ }^{1}$ have been around for a long time and include techniques to account for the constraining effect of the walls on the streamlines in the tunnel, blockage effects from the model and support systems, and buoyancy corrections for any longitudinal or streamwise variations in static pressure in the tunnel. In most cases, simplified geometry representations of the as-designed test section were used in the modeling of these corrections. In fact, early simulations used infinitely long representations of the test section with simplified inviscid wall boundary conditions, and the test article and support system were represented by potential flow singularities. These earlier linear methods began to fail as configurations have advanced to include non-linear lift from vortices, high flow turning from advanced flap systems, or cases where the model causes large blockage or moves significantly off the centerline. Newer wall correction methods have been developed that use arrays of wall pressures to help mitigate these effects.

Numerical simulations have treated the case of a model in the wind tunnel test section in a variety of ways. Many simulations are run by modeling the test configuration in a box made from the dimensions of the test section. The test section walls are modeled as inviscid surfaces and the entrance and exit are simple inflow/outflow boundary conditions. Others have extended the cross section of the test section an arbitrary distance ahead of and behind the model to minimize the effects of the model on the entrance and exit boundaries. In cases where there are significant tunnel effects, the simulations have to be more detailed. Rogers ${ }^{2}$ presented the results of a CFD validation experiment of a semi-span high-lift model that was tested in the NASA Ames 12-ft Pressure Wind Tunnel. A comparison of the experimental and CFD results at the higher lift conditions indicated that CFD had to fully simulate the experiment, which included tunnel walls, splitter plates, etc. The simulations were run with viscous walls, and the test section was extended to provide a simple inlet and exit configuration. When these features of the wind tunnel experiment were incorporated, the CFD results agreed very well with the experiment.

Simple or more conventional tunnel modeling techniques were not sufficient in an unpublished study by the authors of a model in a tunnel with unique contraction characteristics, and a model with a wing span that nearly spanned the walls. CFD predictions did not come close to capturing the lift characteristics of the configuration after simulating the test section alone with the model and the model support system. When the entire settling chamber, contraction, test section and diffuser were modeled, the CFD predictions came very close to matching the experimental results.

The simulations mentioned above might be sufficient for validating CFD methods, but do not provide much information regarding what other things might be affecting the tunnel flow. Experimental data covering the cross section of the test section are rare because they are time consuming and expensive to obtain. Typically there are a few discrete points inside the test section measuring such things as velocity, flow angles, boundary layer profiles, or longitudinal pressures on the tunnel walls. It is more rare to find a facility that has made flow surveys through other parts of the tunnel circuit. When CFD and experiment are used together, those gaps in the experimentalist's knowledge of the facility can be closed.

There have been some attempts in the past to model the high-speed leg of a wind tunnel and these have been performed to provide information regarding some anomaly that is occurring in the tunnel flow. Most notable are the work of Olander ${ }^{3}$ and Wall ${ }^{4}$, where they modeled the high-speed leg of the Volvo Slotted Wall Wind Tunnel. The purpose of the work was to try to identify the cause of an asymmetric pressure distribution on the tunnel walls. They modeled the entire first leg of the Volvo tunnel from the settling chamber to the first diffuser. Extensions were added to the entrance of the settling chamber and exit of the diffuser to create a buffer for the boundaries. A lot was learned regarding flow through the slots and how the boundary layer removal system caused the flow to interact with models in the test section. The cause for the asymmetric pressure distribution could not be identified and it was 
speculated that the entire circuit would need to be simulated to capture the history of the flow before entering the settling chamber.

This paper describes the effort to simulate the high-speed or $1^{\text {st }}$ leg of the NASA Langley $14 \mathrm{x} 22$ - $\mathrm{ft}$ Low Speed Wind Tunnel. This facility was chosen because of the earlier work that was done to calibrate the facility and the flow surveys that were done to identify flow features throughout the entire tunnel circuit. The simulations presented will include two different geometry models for the high-speed leg that consists of the settling chamber, contraction, test section, and first diffuser. Results from two different unstructured grid flow solvers are compared at limited conditions to ensure consistent results.

\section{14 x 22-Ft Low-Speed Wind Tunnel}

The 14 x 22-ft tunnel, shown in Figure 1, was constructed in 1969 to provide an improved understanding of the aerodynamics of vertical/short takeoff and landing (V/STOL) configurations. The tunnel is a closed circuit, atmospheric wind tunnel with a maximum flow velocity in the test section of $338 \mathrm{ft} / \mathrm{sec}$. The test section is $50 \mathrm{ft}$ long. It can be operated in either a conventional closed configuration or in an open test section configuration (sometimes described as $3 / 4$ open) made by raising the ceiling and side walls to form a floor-only configuration. A 9-bladed, $40 \mathrm{ft}$ diameter fan coupled to a 12,000 hp electric motor powers the tunnel.

Figure 2(a) shows a schematic of the tunnel circuit and Figure 2(b) shows a sketch of the tunnel stations that are referenced in this paper. Tunnel station 0.0 and 50.0 are the entrance and exit of the test section, respectively, and tunnel station 192 is the exit of the first diffuser. Tunnel station 7.87 is where measurements of the wall boundary layers were taken during Test 509 just prior to the $1^{\text {st }}$ AIAA High Lift Workshop ${ }^{5}$. Tunnel station 17.75 is at the center of the $1^{\text {st }}$ turntable in the test section and is where models are typically located in the test section. The reference $\mathrm{x}, \mathrm{y}, \mathrm{z}$ coordinate system is located on the centerline of the tunnel circuit at tunnel station 0.0. Gentry ${ }^{6}$ et al. provides a complete description of the tunnel and its flow characteristics.

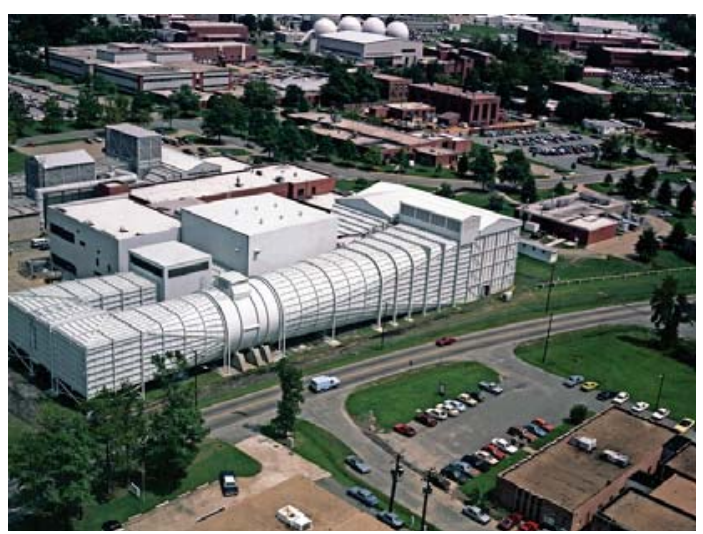

Figure 1. Aerial view of the 14 x 22 -ft Low Speed Wind Tunnel

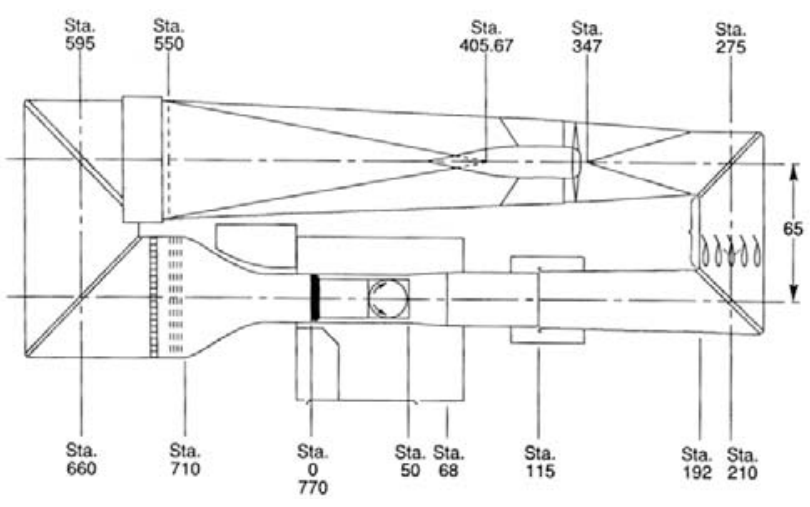

(a) $14 \times 22-\mathrm{ft}$ tunnel circuit

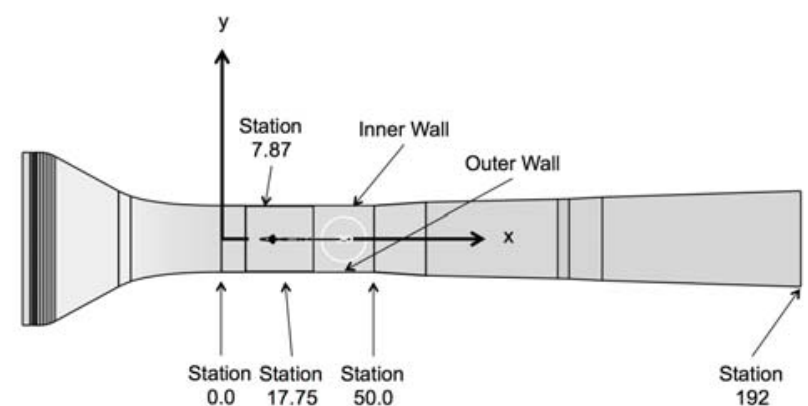

(b) High-speed leg

Figure 2. Wind tunnel schematic and stations 


\section{A. Geometry Development}

Two different methods were used to develop the surface models for grid generation. The first was based on the original 1965 construction drawings for the facility and the second was based on a laser scanning system that produced what is felt to be the "as-built" geometry. Both methods still required engineering judgment and simplification. The boundary layer suction system grate at the test section entrance was modeled as a solid wall. The $14 \times 22$-ft tunnel also has an air exchange vent in the first diffuser that when opened allows fresh air to enter the circuit and is exhausted from the ceiling at the end of the $4^{\text {th }}$ diffuser $(\sim \operatorname{Sta} .560)$. The air exchange vent was faired over for this study.

\section{Construction Drawings}

Construction drawings of the tunnel circuit were used to provide the "as-designed" baseline for this study. The geometry data consisted of cross sections throughout the tunnel circuit. Certain cross-sections that are exposed to the outside elements (e.g., rain) were designed to have a $300-\mathrm{ft}$ radius on the ceiling for water runoff. No information was provided on how the ceiling transitioned from flat to curved, so the cross sections were left as flat. The settling chamber and contraction were simplified in that all the details of the honeycomb and screens have been omitted.

\section{Laser-scanned Point-cloud}

NASA Langley is embarking upon a process to define the geometry of several of the Center's heavily used facilities. The data obtained will serve two purposes; 1) provide a detailed description of the "as-built" condition of the facility that can be used to track changes over time, and 2) provide a digital geometric description that can serve to develop computational grids at a later date.

The GIS team at NASA Langley used laser-scanning techniques to provide surface measurements with an overall accuracy to within a centimeter throughout the $14 \times 22-\mathrm{ft}$ tunnel circuit. The point cloud obtained for the closed test section configuration contained approximately 159 million points for the high-speed leg and 587 million points for the entire circuit. The point cloud was transferred to the GeoLab group at NASA Langley to process the point cloud into surfaces to be used for grid generation purposes.

The GeoMagic $®$ software program was used to manually down-sample the point cloud to a particular entity of interest (e.g., test section), and features that were not of interest for this work were excluded (e.g., windows, doors). A best-fit plane/cylinder shape was fit to the points of interest and the deviations from the points were checked to determine if additional points should be added or removed. This process was repeated until a satisfactory fit was obtained. The resulting surface was imported into the Uniqraphics ${ }^{\circledR}$ CAD program to match up the new surface to adjacent features. The Unigraphics surfaces were then imported back into Geomagic software to again check the deviations from the scanned points. This process of matching surfaces in Unigraphics and Geomagic was continually iterated until suitable surfaces were obtained. Once surfaces for the high-speed leg were obtained, they were then ready for the grid generation process described below.

The laser-scanned surfaces provide details that were not readily available in the construction drawings. The fairing in the contraction that smooth's the flow over the mounting hardware for the honeycomb and screens were identified. The $300 \mathrm{ft}$ radius on the ceiling at several stations in the first diffuser was identified as well as the transitions from the flat to curved ceilings. Most of the deviations between the construction drawings and scanned surfaces were on the order of a few inches.

\section{Numerical Modeling Approach}

The computations presented in this paper were obtained using the NASA Tetrahedral Unstructured Software System $^{7}$ (TetrUSS) that was developed at NASA Langley Research Center (LaRC). The system is comprised of several loosely integrated software packages that allow the user to start with a geometry, typically in a CAD or Plot3D format, then generate surface definitions and tetrahedral volume grids for use with the flow solver. The surface definition package GridTool ${ }^{8}$ allows the user to set up surface patches, boundary conditions, and viscous spacing requirements. The volume grid software package VGRID takes the files from GridTool and uses the Advancing Layers Method ${ }^{9}$ (ALM) to generate thin-layered viscous cells and the Advancing Front Method ${ }^{10}$ (AFM) to generate the inviscid field cells. The package also contains an unstructured grid flow solver USM3D. Some simulations were also carried out using the unstructured grid solver FUN3D, which can read the grid files generated 
by VGRID. The Reynolds number for the simulations was $1.7108 \times 10^{6}$ per ft, or $150.1 \times 10^{6}$ based on the $87.75 \mathrm{ft}$ run length from the start of the contraction to tunnel station 17.75. The target Mach number was 0.2678, which matched a test point of $\mathrm{q}=101.5 \mathrm{lb} / \mathrm{ft}^{2}$.

\section{B. Flow Solvers}

\section{USM $3 D$}

The Reynolds averaged Navier-Stokes code, USM3D, described in reference 7, was used for most of the data presented in this paper. USM3D is a cell-centered, upwind-biased, finite volume flow code that solves the compressible Euler and Navier-Stokes equations on tetrahedral unstructured grids. The computations were performed using 96 processors on the Pleiades Supercomputer at NASA Ames Research Center. Computations were performed as fully viscous solutions using the Spalart-Allmaras (SA) turbulence model for comparison with the wind tunnel data.

\section{FUN3D}

The Reynolds averaged Navier-Stokes code, FUN3D ${ }^{11,12,13}$ is a finite-volume, node-based flow solver. FUN3D solves the flow equations on mixed element grids, including prisms, tetrahedra, and pyramids. For the tetrahedral meshes used in this study, the full viscous fluxes are discretized using a finite-volume formulation in which the required velocity gradients on the dual faces are computed using the Green-Gauss theorem. On tetrahedral meshes this is equivalent to a Galerkin type approximation. The Spalart-Allmaras (SA) turbulence model was used in this study. The computations were performed on the K-Cluster at NASA Langley Research Center using 96 processors.

\section{Grid Generation}

The computational grids were developed using the VGRID unstructured grid generator, which is a part of the TetrUSS system described above. Figure 3 shows a typical surface grid for the high-speed leg. The viscous spacing was determined by specifying the Reynolds number and viscous wall first cell height of $\mathrm{y}^{+}=0.5$. Stretching parameters were then specified that blend the viscous grid into the background inviscid grid. For the results presented in this paper, solutions were obtained with a grid of approximately 33 million tetrahedral cells and 5.6 million nodes. Additional grids have been developed for examining the Mach number and pressure distributions on the centerline and those grid sizes approached 38 million cells.

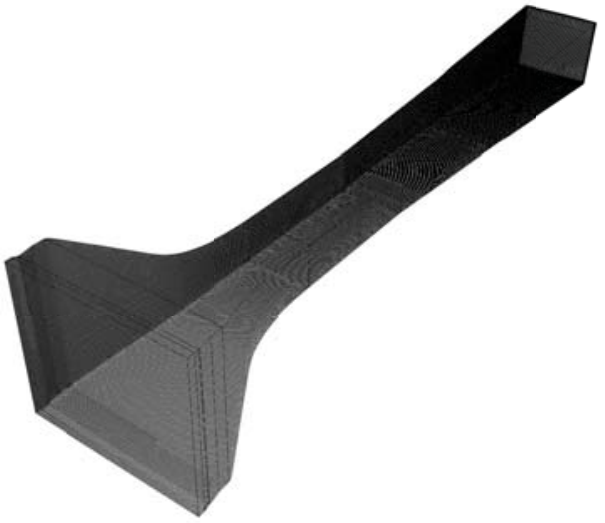

(a) Overall all view

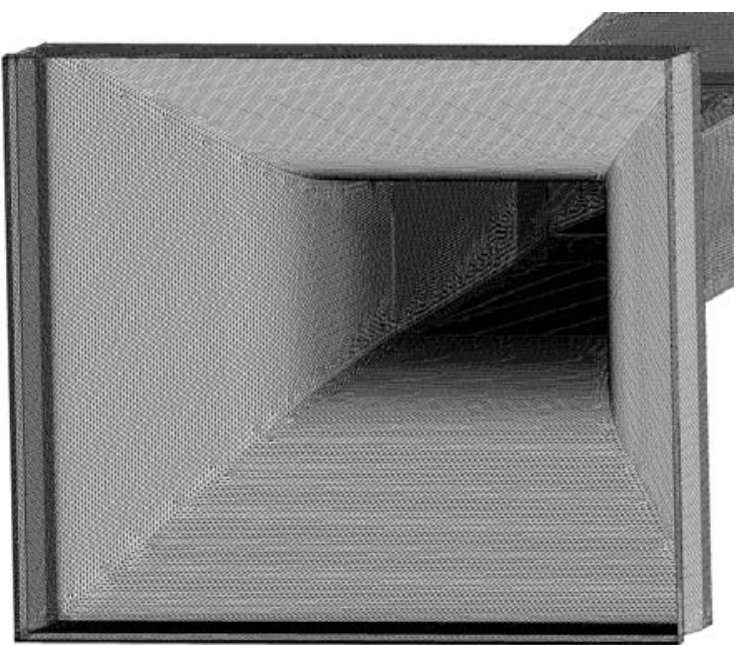

(b) Close-up of the Contraction

Figure 3. Surface grid 


\section{Boundary Conditions (BC)}

The selection and application of the appropriate boundary conditions was an integral part of this study. At the entrance to the settling chamber, a jet boundary condition available in USM3D, or a subsonic inflow boundary condition in FUN3D, was applied. In both solvers, a backpressure (static pressure) boundary condition at the exit of the first diffuser was applied. The procedures used to set the tunnel speed in the test section depended on the static pressure that was imposed at the diffuser exit (exit BC).

\section{USM3D Boundary Conditions}

The jet boundary condition (102) was used to define the inflow boundary conditions in the settling chamber. The jet boundary condition was set by defining the total pressure and total temperature at the entrance plane. These values were obtained from the tunnel data acquisition system for the appropriate test condition. The internal outflow (1002) boundary condition extrapolates density and velocities, and sets the static pressure to a constant freestream value on the outflow boundary. Total enthalpy is also imposed at the exit boundary. To set the desired test section conditions, the static pressure at the exit of the diffuser was set to a value $\left(\mathrm{p}_{\mathrm{set}}\right)$ that was then iterated until the desired target Mach number was reached at tunnel station 17.75.

\section{FUN3D Boundary Conditions}

The subsonic inflow boundary condition (7011) was used to set the inflow boundary conditions in the settling chamber. The inputs required for this $\mathrm{BC}$ are the total pressure ratio $\left(\mathrm{p}_{\mathrm{t}} / \mathrm{p}_{\infty}\right)$ and the total temperature ratio $\left(\mathrm{T}_{t} / \mathrm{T}_{\infty}\right)$ and these were obtained from the tunnel data acquisition system for the appropriate test condition. The pressure outflow boundary condition (5051) was used to set the static pressure $\left(\mathrm{p}_{\mathrm{set}}\right)$ at the exit of the diffuser. For a subsonic outflow boundary condition the static pressure ratio $\left(\mathrm{p}_{\mathrm{set}} / \mathrm{p}_{\infty}\right)$ is specified, and the velocities and temperature are extrapolated. To set the desired test section conditions, the static pressure ratio at the exit of the diffuser was set to a value $\left(\mathrm{p}_{\mathrm{set}} / \mathrm{p}_{\infty}\right)$ that was then iterated until the desired target Mach number was reached at tunnel station 17.75.

\section{Results}

Data will be presented by first comparing limited results obtained using the two different flow solvers to demonstrate consistency of the solutions. Further evaluation of the flow characteristics in the first leg and a comparison between the "as-designed" and "as-built" results will then be presented using the USM3D flow solver.

\section{E. Flow Solver Comparison}

In this section, a limited comparison of the flow in the high-speed leg from the USM3D and FUN3D simulations are presented. It was recognized that running the exact same grid in USM3D and FUN3D would mean that FUN3D was running on an effectively much coarser grid. The results are based on the "as-built" geometry. Mach contours on the horizontal plane at $\mathrm{z}=0.0$ (tunnel centerline) in the high-speed leg are shown in Figure 4. Both solvers show a smooth transition from the low-speed flow in the settling chamber, accelerating to a uniform Mach number in the test section, then a deceleration of the flow in the $1^{\text {st }}$ diffuser. Figure 4(a) shows that USM3D predicts a velocity deficit on the outer wall of the $1^{\text {st }}$ diffuser near the exit. The reason for the deficit is still under investigation. Neither code predicts any separated flow in the high-speed leg. Figure 5 shows the Mach profiles on the centerline of the high-speed leg of the tunnel. The results are very similar and show the same slight acceleration of the flow in the test section. Figure 6 shows a profile of the Mach number at reference station 17.75 after the iteration process of the backpressure in the $1^{\text {st }}$ diffuser. The process used to set the target Mach number in the test section was successful and both solvers provided very similar results. Based on the excellent comparisons, in the following portions of the paper, only the results from the USM3D solver are presented. 


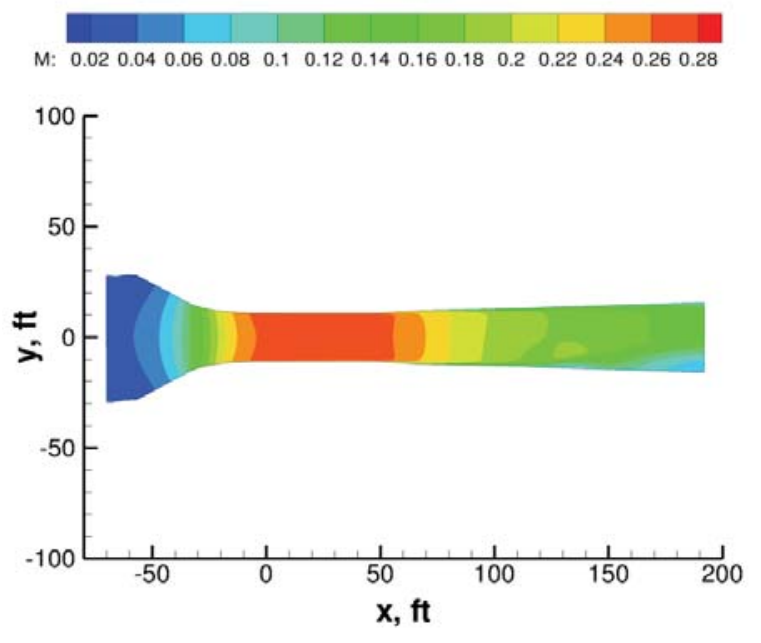

(a) USM3D

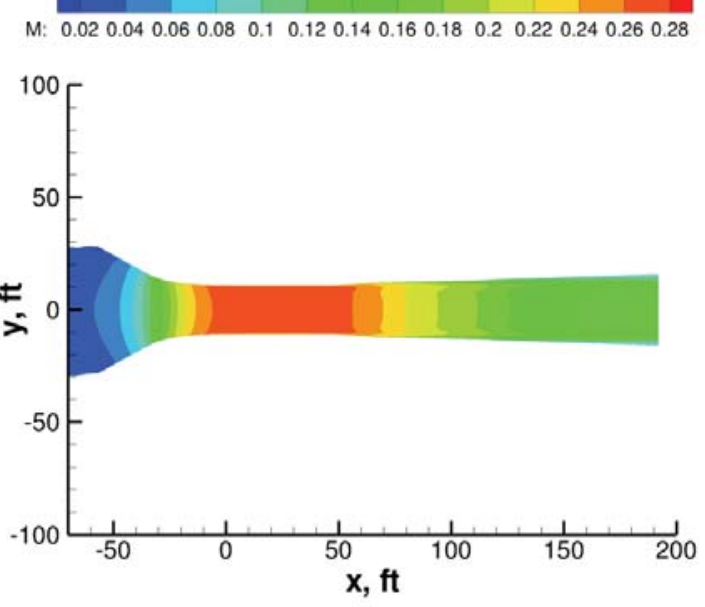

(b) FUN3D

Figure 4. Comparison of Mach contours, horizontal plane at $\mathrm{z}=\mathbf{0 . 0}$

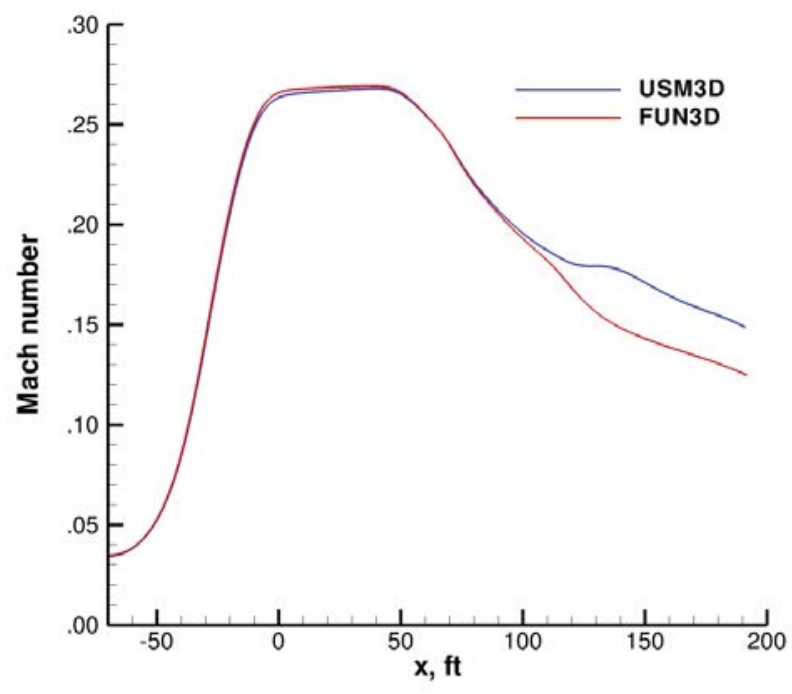

Figure 5. Comparisons of Centerline Mach Profiles 


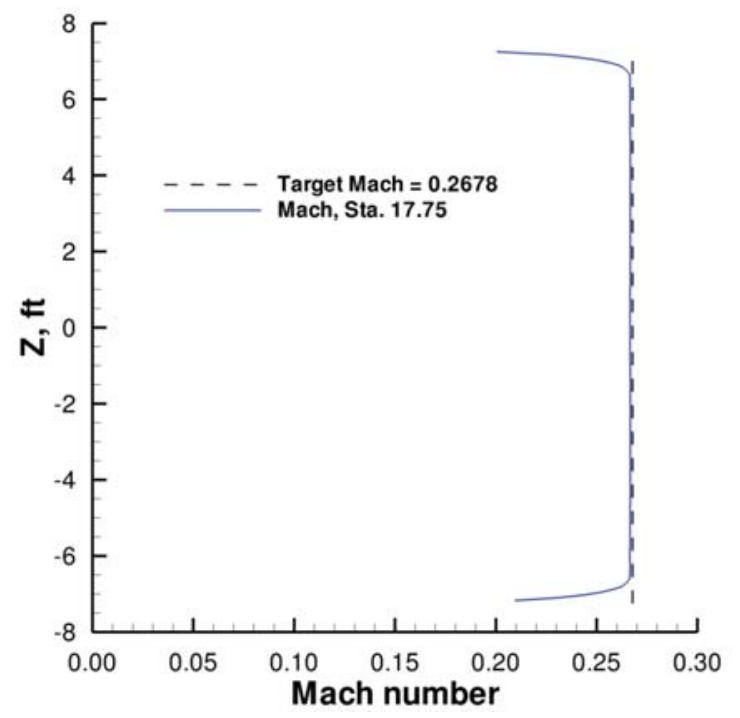

(a) USM3D

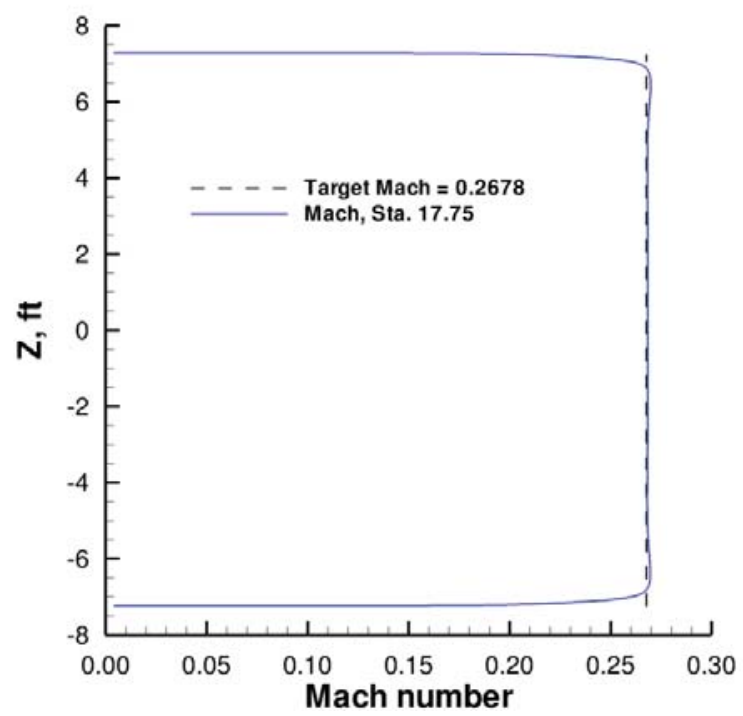

(b) FUN 3D

Figure 6. Comparison of Mach Profiles, Sta. $=17.75$

\section{F. Flow Field Predictions}

Figure 7 shows the static pressure along the centerline of the tunnel. Computational results are compared with experimental data from Reference 6. The experimental results were obtained through the use of a centerline probe, which spanned the distance from $20 \mathrm{ft}$ into the contraction to the end of the test section. The experimental data show that the static pressure decreases $0.0959 \mathrm{psf} / \mathrm{ft}$ from Sta. 5 to Sta. 30. A further decrease in static pressure occurs between Sta. 30 to 40 as the free stream flow adjusts to the 3 - $\mathrm{ft}$ slot opening in the tunnel walls. Those slots are not modeled in the simulations as they are now permanently closed in the facility. Figure 7 shows that the simulation predicts pressures in the contraction very well, but slightly under predicts the pressure gradient in the test section. Future work will include modeling the centerline probe and supporting structure.

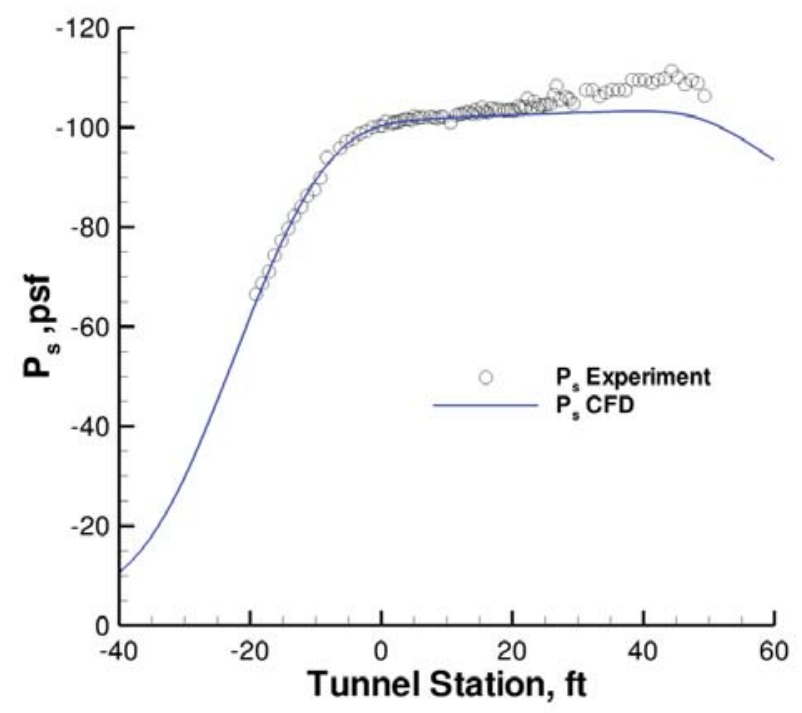

Figure 7. Comparison of predicted longitudinal static pressure distribution with experiment ${ }^{6}$

The following comparisons are made using data, which is more recent than what was published in Reference 6. The experimental wall pressures and the boundary layer measurements are from Test 509, Run 137, and Point 1515. 
Figure 8 shows a comparison between the simulated and measured wall pressures coefficients. Figure 8(a) provides a sketch of the rows on the walls and ceilings where pressure ports are located. Figure 8(b) shows the wall pressure coefficients on the ceiling and Figure 8(c) and 8(d) show the inner and outer sidewall pressure coefficients. There appears to be a subtle kink in the experimental $\mathrm{Cp}$ distribution that shows up on the ceiling and inner sidewall around tunnel station 18 to 20 . The simulations provide smooth $C_{p}$ distributions on the walls and ceiling, and under predict the slope.

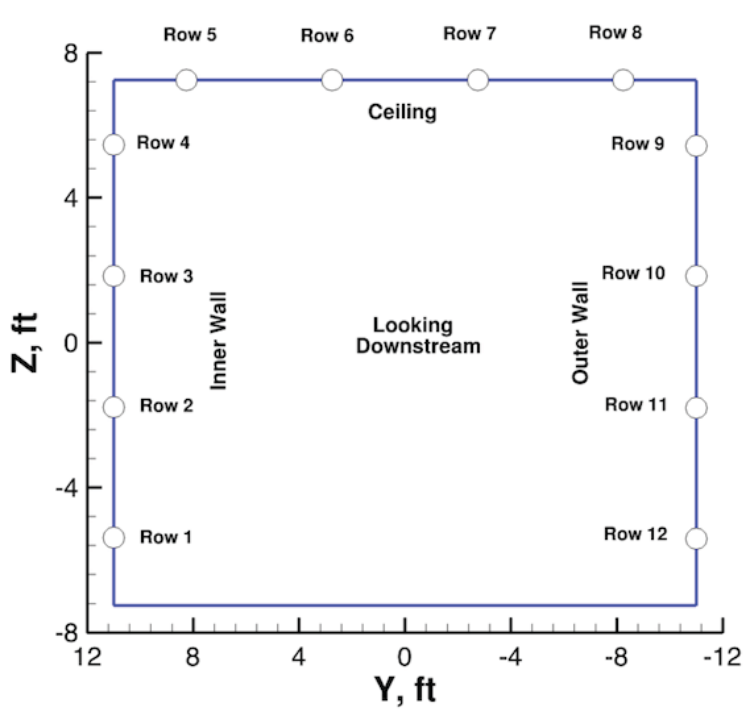

(a) Wall pressure port locations

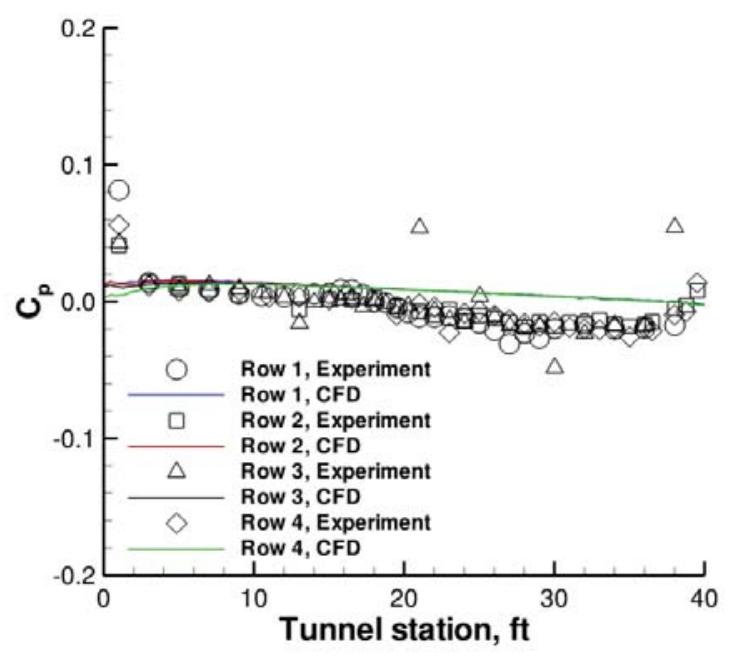

(c) Inner wall

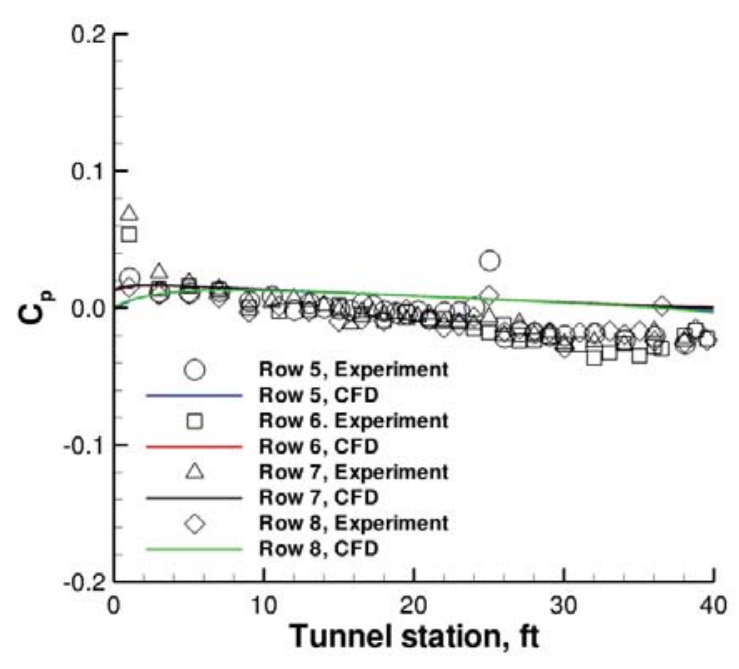

(b) Ceiling pressures

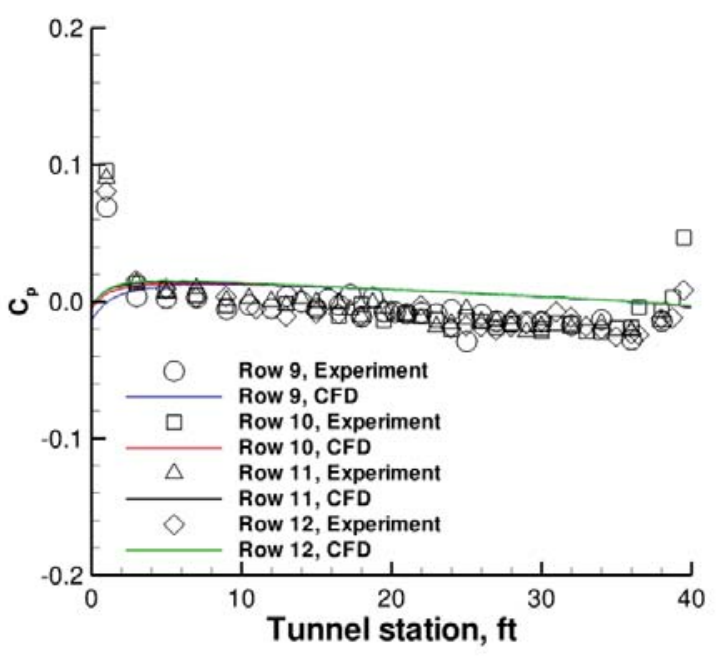

(d) Outer wall

Figure 8. A Comparison of wall pressure coefficients, $q=101.5 \mathrm{psf}$

In all of the simulations, the boundary layer is allowed to grow naturally all the way from the settling chamber to the exit of the diffuser. Figure 9 shows a comparison between the measured and predicted boundary layer at Station 7.87. It is presented using non-dimensional $\mathrm{y}^{+}$and $\mathrm{u}^{+}$law of the wall coordinates to evaluate how well the structure of the turbulent boundary layer is captured. The experimental data was obtained by taking the measured velocity from a boundary layer probe in the test section and transforming to non-dimensional units by the Clauser ${ }^{14}$ method and then comparing the data to Spalding's curve ${ }^{15}$. The numerical results pick up the buffer region and wake region very well and match the slope of the log-law portion of the boundary layer. 


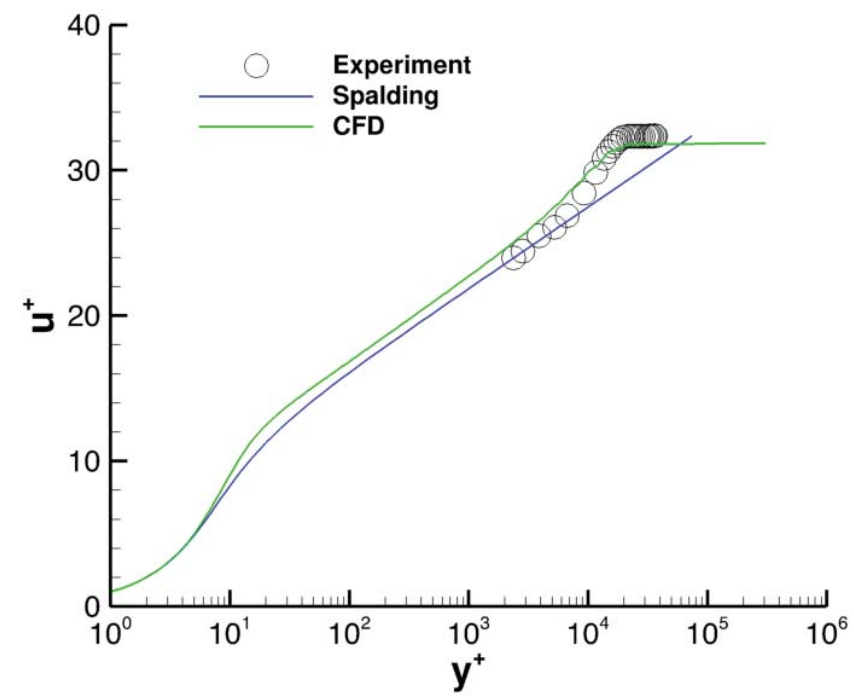

Figure 9 Boundary layer profile on the floor, Sta. $=7.87, y=-3.0 \mathrm{ft}, \mathrm{q}=100 \mathrm{lb} / \mathrm{ft}^{2}$

\section{G. Geometry comparison}

Data presented in this section will compare the effects of using the construction drawings, or "as-designed" surfaces, to the laser-scanned "as-built" surfaces. Mach contours for the horizontal plane $\mathrm{z}=0.0$ in the high-speed leg are shown in Figure 10. There is a slight difference in the settling chamber and the entrance to the contraction due to fairing over the screen and honeycomb supports. There is also a small difference in the region of the $1^{\text {st }}$ diffuser air intake (Sta. 115) that is due to slightly different ways of fairing over the intake vents. The small region of reduced Mach number at the exit of the $1^{\text {st }}$ diffuser is still present, but is much less pronounced with the "as-built" surfaces. More work is needed to determine if this is due to the fairings over the intake flaps.

Mach contours for a vertical $(\mathrm{y}=0.0)$ plane on the tunnel centerline are shown in Figure 11. Using the "asdesigned" geometry there is again a region of reduced Mach number near the floor at the exit of the $1^{\text {st }}$ diffuser. Using the "as-built" geometry, no anomalies appear near the floor.

M: $\begin{array}{lllllllllllllllll}0.02 & 0.04 & 0.06 & 0.08 & 0.1 & 0.12 & 0.14 & 0.16 & 0.18 & 0.2 & 0.22 & 0.24 & 0.26 & 0.28\end{array}$

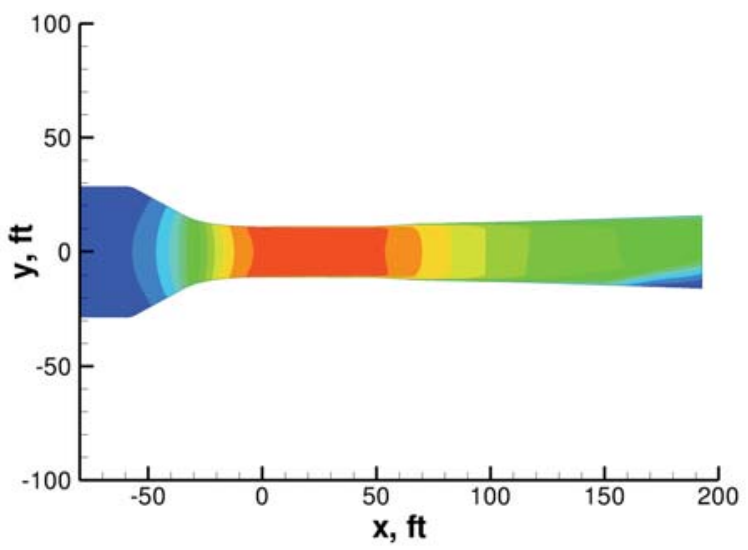

(a) Construction drawings

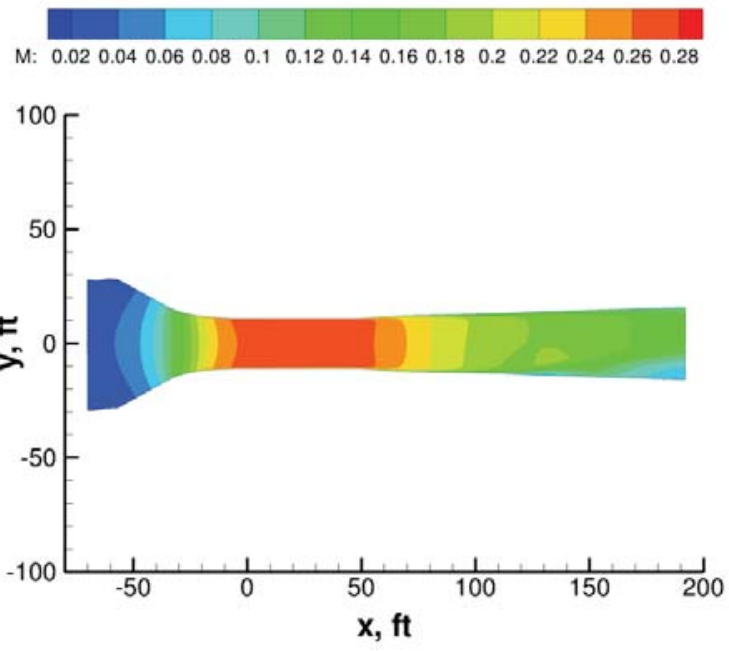

(b) Scanned surfaces

Figure 10. Comparison of Mach contours in the high speed leg, horizontal plane at $\mathrm{z}=\mathbf{0 . 0}$ 


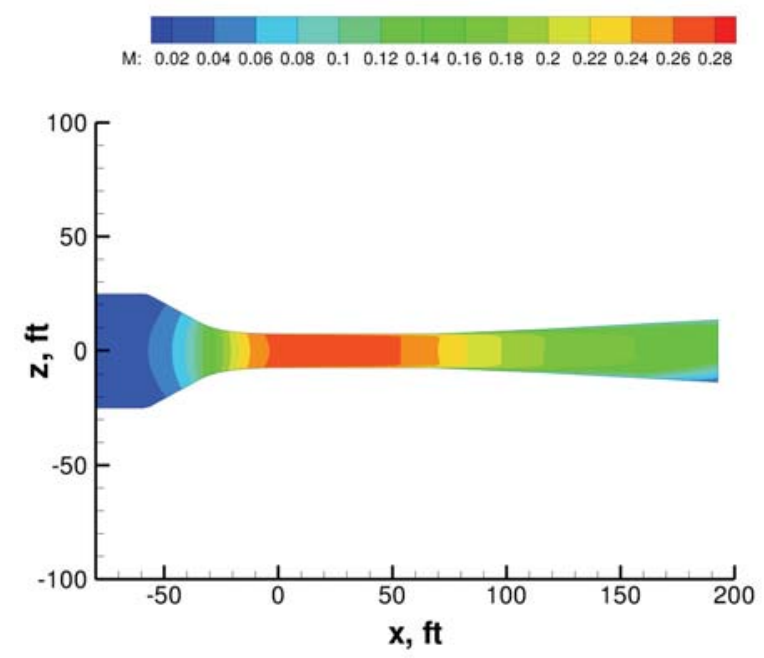

(a) Construction drawings

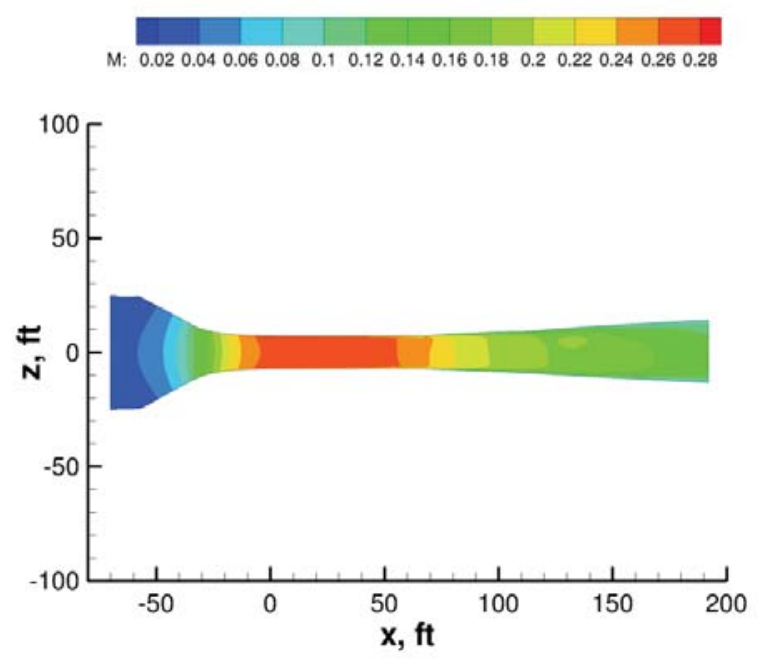

(b) Scanned surfaces

Figure 11. Comparison of Mach contours of the high speed leg, vertical plane at $\mathbf{y}=\mathbf{0 . 0}$

Figure 12 shows the Mach number profile at station 17.75 for both sets of geometries. Both geometry definitions provide a uniform profile at tunnel station 17.75. Figure 13 shows a comparison of the boundary layer profiles and a nearly identical profile is obtained in both cases.

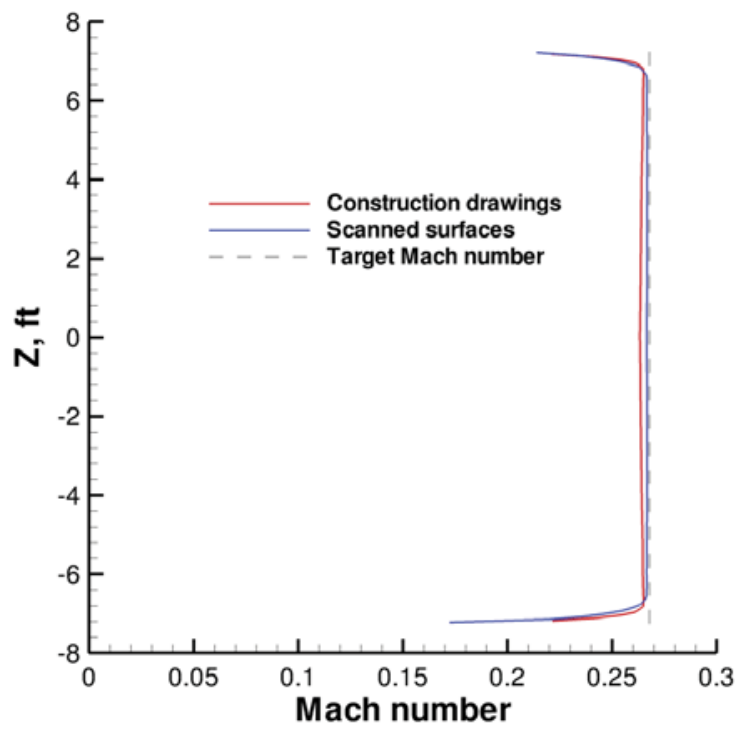

Figure 12. Mach profile, $y=0.0$, Sta. $=17.75$

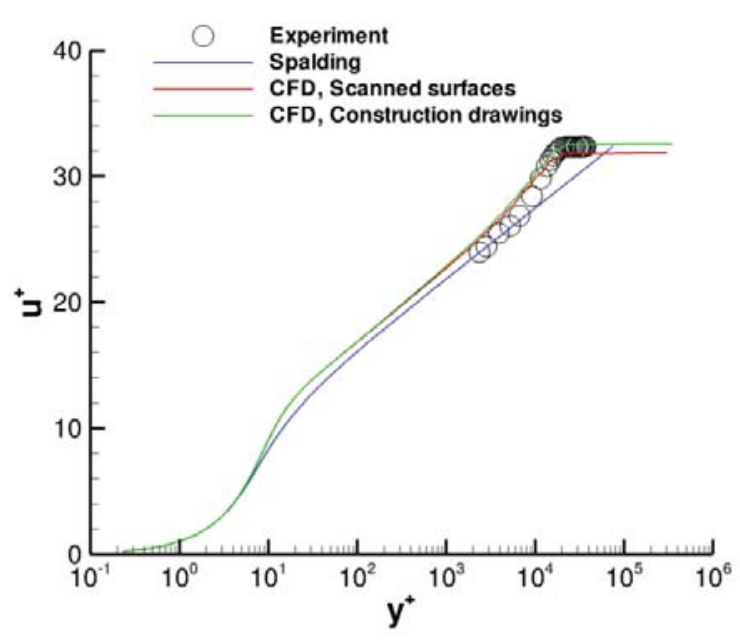

Figure 13. Boundary layer profile on the floor, Sta. $=7.87, y=-3.0 \mathrm{ft}, q=100 \mathrm{lb} / \mathrm{ft}^{2}$

Flow angularity can detect small changes in the flow field and present a picture of the flow uniformity in the test section. Figure 14 shows a comparison of the predicted upwash angle $\Delta \alpha$, in degrees, for cross sections at several stations throughout the test section for the two geometry definitions. In either case, corner vortices formed due to the straight $90 \mathrm{deg}$ wall corners in the contraction and test section are clearly visible. Both cases show these 
disturbances tend to dissipate as the flow travels down the test section. The upwash angles based on the "asdesigned" geometry are very uniform and the corner disturbances are generally symmetrical and decaying toward the end of the test section. The upwash angles based on the "as-built" geometry show much stronger and asymmetrical disturbances near the tunnel floor. Near the end of the test section a strong disturbance on the inner wall near the floor still remains. An investigation is underway to determine the discrepancy.

Upwash is a commonly used parameter for correcting experimental data in the tunnel. Experimentally the upwash angle is determined by conducting an alpha sweep with a check-standard model in the tunnel in both an upright and inverted configuration. Half the distance between the two lift curves provides a measure of an integrated (over the span of the wing) upwash angle. Reference 6 states that at the time of publication, the indicated upwash angle was approximately 0.15 degree. Comparing the CFD predicted upwash angles at $\mathrm{z}=0.0$ in Figure 14(c) and (d), the upwash angles range from near zero (about 0.005) deg for the "as-designed" geometry to about 0.1 deg for the "as-built" geometry. The "as-built" CFD data is closer to that measured with the check standard model. Future work may include simulating an alpha sweep with the check standard model in the test section and comparing with the experimentally derived integrated upwash angle. 


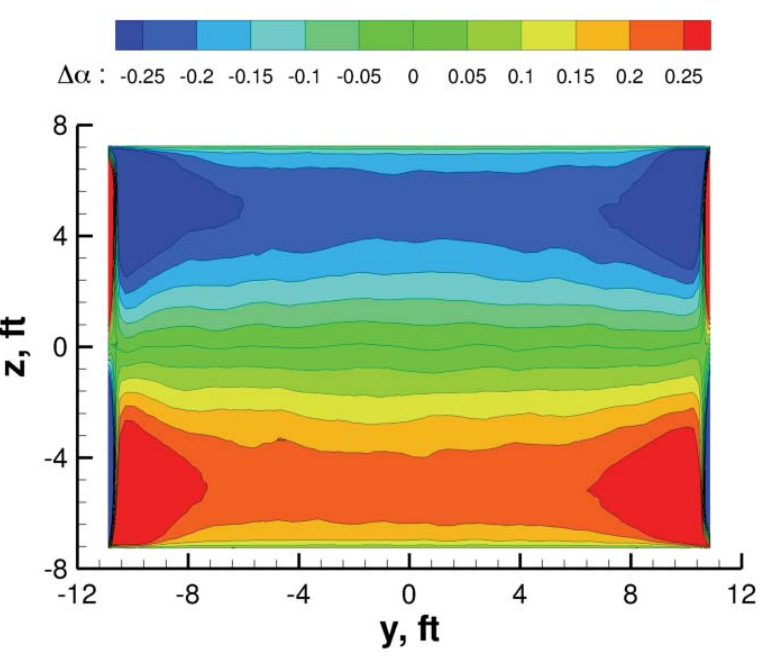

(a) Construction Drawings, Sta. 0.0

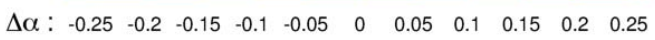

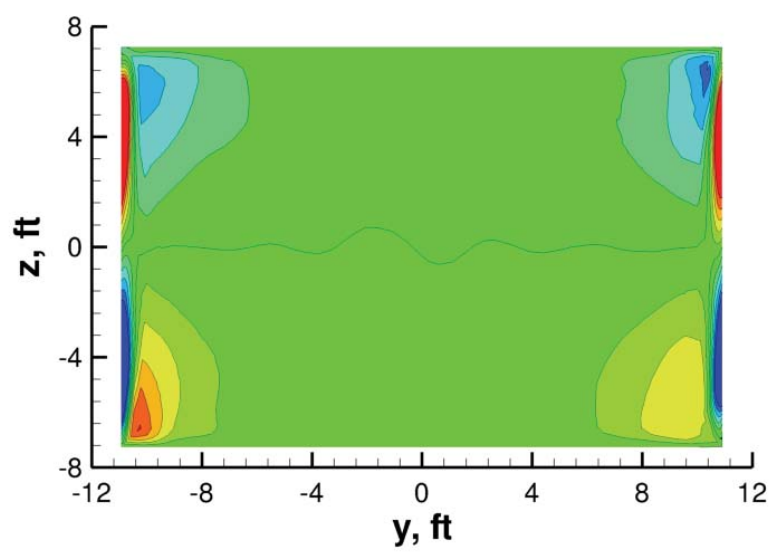

(c) Construction Drawings, Sta. 17.75

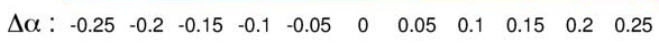

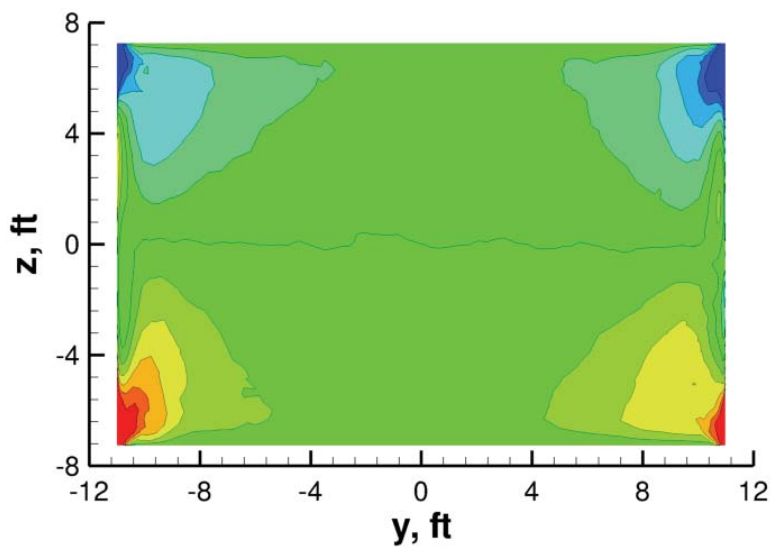

(e) Construction Drawings, Sta. 50.

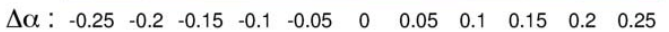

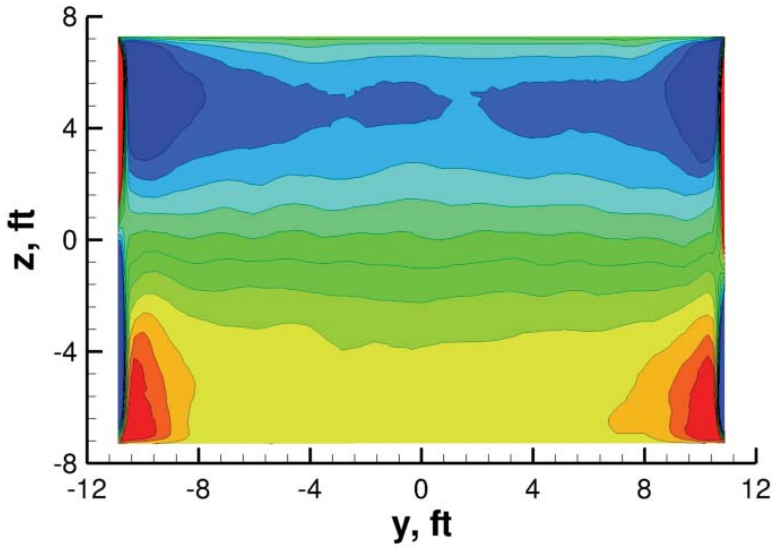

(b) Scanned Surfaces, Sta. 0.0

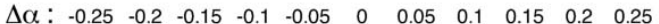

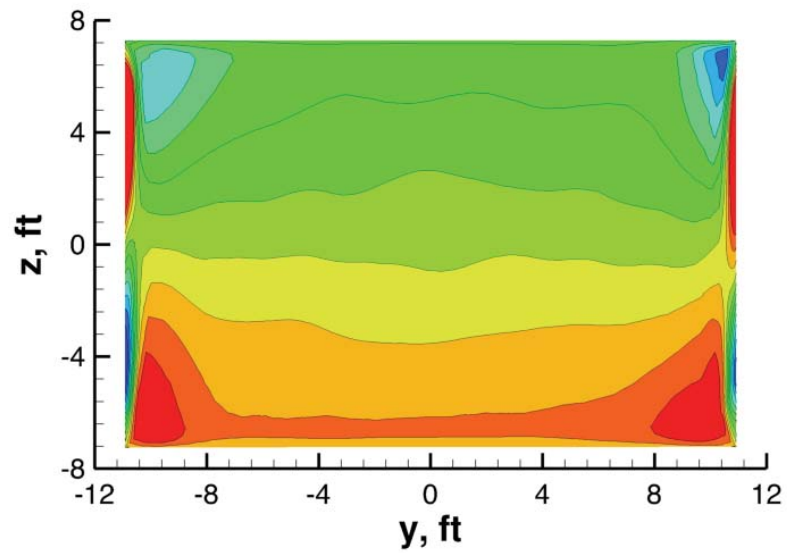

(d) Scanned Surfaces, Sta. 17.75

$\begin{array}{llllllllllll}\Delta \alpha: & -0.25 & -0.2 & -0.15 & -0.1 & -0.05 & 0 & 0.05 & 0.1 & 0.15 & 0.2 & 0.25\end{array}$

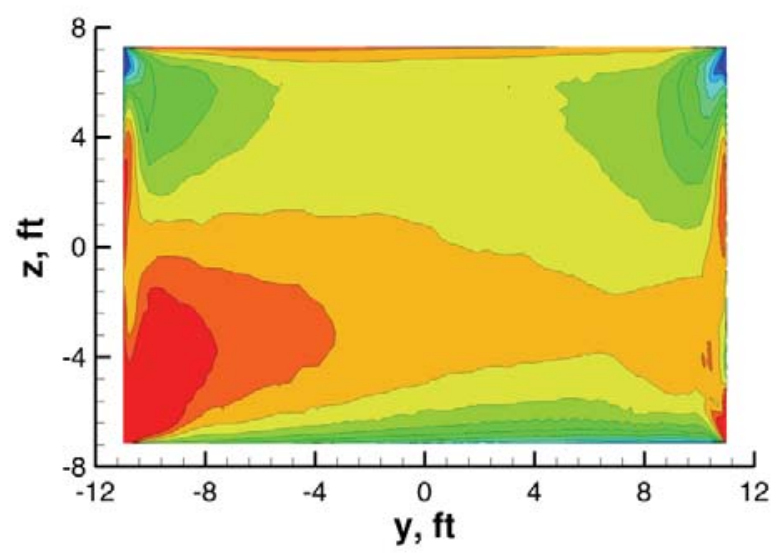

(f) Scanned Surfaces, Sta. 50.

Figure 14 Comparison of Contours of upwash angle along the Test Section 


\section{Concluding Remarks}

Numerical simulations of the high-speed leg of the NASA Langley 14 x 22-ft wind tunnel have been presented. Results from two different flow solvers and two different geometry standards are shown. The two geometry standards represent an "as-designed" and an "as-built" comparison. The two flow solvers have been shown to provide very similar results. The two geometry standards show generally overall agreement. For more sensitive measurements like upwash, the "as-built" geometry was far superior. The upwash angles based on the "as-built" geometry show values closer to the experimentally measured upwash, but also show a strong asymmetry in the corners near the floor at the exit of the test section.

\section{Future Work}

With the knowledge gained from this study, work has begun on a simulation of the entire $14 \mathrm{x} 22$-ft wind tunnel circuit. Laser scans have documented the "as-built" geometry with the construction drawings filling in information as needed. The simulation will include the fan drive system, the 410 turning vanes in the corners, and the five flow control vanes. Simulating the entire facility will provide a much better understanding of the flow characteristics throughout the circuit and help guide future facility improvements.

\section{Acknowledgments}

Funding for this work has been provided by Research Directorate of NASA Langley Research Center under the LASER0175 contract. The authors would like to thank William Ball of NASA Langley and Jason Hall of Stinger Ghaffarian Technologies (SGT) for their efforts in providing the laser-scanned point-cloud data for this investigation. The authors would like to thank Luther Jenkins of NASA Langley and the team of researchers that obtained the boundary layer measurements for the $1^{\text {st }}$ AIAA CFD High Lift Flow Workshop (HiLiftPW-1). The authors would also like to thank Judi Hannon of NASA Langley for sharing her insights regarding the 14 x $22-\mathrm{ft}$ tunnel and the facility measurements. 


\section{References}

1 AGARDograph 36, Wind Tunnel Wall Corrections, B.F.R. Ewald, (Editor), October 1998.

2 Rogers, Stuart, E. and Roth, Karlin: "CFD Validation of High-Lift Flows With Significant Wind-Tunnel Effects" AIAA Paper 2000-4218, $18^{\text {th }}$ AIAA Applied Aerodynamics Conference, 14-17, Denver, CO, August 2000

3 Olander, Mattias: "CFD Simulation of the Volvo Cars Slotted Wind Tunnel", Masters Thesis 2011:33, Chalmers University of Technology, Dept. of Applied Mechanics, 2011

4 Wall, Anette: "Simulating the Volvo Cars Aerodynamic Wind Tunnel with CFD", Masters Thesis 2013:08, Chalmers University of Technology, Dept. of Applied Mechanics, 2013

5 Rumsey, C., Slotnick, J., Long, M., Stuever, R., Wayman, T., "Summary of the First AIAA CFD High Lift Prediction Workshop," AIAA-2011-939, Jan 2011.

6 Gentry, Garl L., Jr., Quinto, P. Frank, Applin, Zachary T.: "The Langley 14- by 22-Foot Subsonic Tunnel: Description, Flow Characteristics, and Guide for Users" NASA TP-3008, September, 1990.

7 Frink, N. T., Pirzadeh, S. Z., Parikh, P. C., Pandya, M. J., and Bhat, M.K.: "The NASA Tetrahedral Unstructured Software System," The Aeronautical Journal, Vol. 104, No. 1040, October 2000, pp. 491-499

8 Samareh, J. A.: "GridTool: A Surface Modeling and Grid Generation Tool", Proceedings of the Workshop on Surface Modeling, Grid Generation, and Related Issues in CFD Solutions, NASA Lewis Research Center, Cleveland, OH, NASA CP-3291, 1995, May 9-11, 1995

9 Pirzadeh, S. Z.: "Three Dimensional Unstructured Grids By The Advancing Layer Method," AIAA Journal, Vol. 33, No. 1, 1996, pp. 43-49

10 Lohner, R. and Parikh, P., "Three-Dimensional Grid Generation By The Advancing Front Method," International Journal for Numerical Methods in Fluids," Vol. 8, Issue 10, 1988, pp. 1135-1149

11 Anderson, W. K. and Bonhaus, D. L., "An Implicit Upwind Algorithm for Computing Turbulent Flows on Unstructured Grids," Computers and Fluids, Vol. 23, No. 1, 1994, pp. 1-22

12 Anderson, W. K., Rausch, R. D., and Bonhaus, D. L., "Implicit/Multigrid Algorithm for Incompressible Turbulent Flows on Unstructured Grids," AIAA Paper 95-1740, 1995.

13 Nielsen, E. J., Aerodynamic Design Sensitivities on an Unstructured Mesh Using the Navier-Stokes Equations and a Discrete Adjoint Formulation, Ph.D. thesis, Virginia Polytechnic Institute and State University, 1998.

14 Clauser, Francis H.: "Turbulent Boundary Layers in Adverse Pressure Gradients", Journal of the Aeronautical Sciences, Vol. 21, No. 2, 1954, pp. 91-108.

15 Spalding, D. B., "A Single Formula for the Law of the Wall," J. Applied Mechanics, Transaction of the ASME, Series E., Vol. 83, 1961, p. 455. 